\title{
Predictive Values of Inflammatory Cell Ratios for Complexity of Coronary Artery Disease in Patients with Acute Coronary Syndrome
}

\author{
Ahmet Karakurt, Cennet Yildiz ${ }^{1}$ \\ Department of Cardiology, Faculty of Medicine, Kafkas University, Kars, 'Department of Cardiology, Bağcilar Tekden Hospital, İstanbul, Turkey
}

\section{Abstract}

Background: The aim of this study was to investigate the relationship between neutrophil to lymphocyte ratio (NLR) platelet to lymphocyte ratio (PLR), mean platelet volume to lymphocyte ratio (MPVLR), MPV to platelet ratio (MPVPR) and the complexity of coronary artery disease (CCAD) in patients with acute coronary syndrome (ACS) using the SYNTAX score (SS) algorithm. Materials and Methods: A total of 599 patients with ACS undergoing coronary arteriography were enrolled and divided into three groups according to their SS: low SS group $\leq 22$ (low-SSG,); intermediate SSG $\geq 23$ and $\leq 32$ (in-SSG,); and high- SSG $\geq 33$ (high-SSG). Routine complete blood count parameters were analyzed at hospital admission. Results: There were significant differences between three groups in terms of PLR and MPVLR values $(P=0.007$ and $P=0.029)$. Correlation analysis showed that PLR and MPVLR were positively correlated with CCAD $(r=0.095, P=0.018$ and $r=0.112, P=0.005$, respectively). In multivariate logistic regression analysis, MPVLR was not an independent predictor of CCAD, whereas PLR was found to be a weak independent predictor of CCAD (odds ratio $=1.003$ [1.001-1.006], $P=0.021$ ). Receiver operating characteristics analysis showed that PRL had low sensitivity (56.2\%) and specificity (51.6\%) for prediction of CCAD. Conclusion: Our study showed that NLR, MPVPR, and MPVLR were not independent predictors of CCAD in patients with ACS. PLR had such a weak relationship with CCAD that it could not be used for prediction of CCAD in these patients.

Keywords: Acute coronary syndrome, complexity of coronary artery diseases, inflammatory cell ratios

\section{INTRODUCTION}

Atherosclerosis is a low-grade inflammatory disease that results in atherosclerotic plaque formation and progressive stenosis of the coronary arteries..$^{[1-3]}$ Inflammation plays an important role in all stages of atherosclerosis, from initiation and growth to complication of plaque including unstable angina pectoris (USAP), non-ST-elevation myocardial infarction (non-STEMI) and STEMI. ${ }^{[4,5]}$

The SYNTAX scoring (SS) system, based on qualitative and quantitative characterization of coronary artery disease (CAD) by including 11 angiographic variables that take into consideration lesion location and characteristics, is a valuable method for estimating the severity of CAD. ${ }^{[6]}$ The severity of coronary artery lesions assessed by the SYNTAX score (SS) is associated with long-term mortality and major adverse cardiac event rates..$^{[7-10]}$

\begin{tabular}{|l|l|}
\hline \multicolumn{2}{|c|}{ Access this article online } \\
\hline Quick Response Code: & Website: \\
\hline & http://www.ijcva.com \\
\cline { 2 - 2 } & \\
\hline
\end{tabular}

Increased neutrophil to lymphocyte ratio (NLR), platelet to lymphocyte (PLR), mean platelet volume (MPV), MPV to lymphocyte ratio (MPVLR), and MPV to lymphocyte ratio (MPVPR) have been shown to play a role in the pathophysiology of atherosclerotic disease. It has been reported that increased values of NLR, PLR, MPV, and MPVLR are associated with cardiovascular diseases. ${ }^{[11-15]}$ In addition, these parameters have been shown to be related to the development of acute coronary syndrome (ACS) and found to be a predictor of morbidity and mortality in patients with ACS. ${ }^{[16-21]}$ However, few reports have investigated so far the relationship between these parameters and the

Address for correspondence: Dr. Ahmet Karakurt, Department of Cardiology, Faculty of Medicine, Kafkas University, Kars 36100 , Turkey. E-mail: karakurt38@hotmail.com

This is an open access journal, and articles are distributed under the terms of the Creative Commons Attribution-NonCommercial-ShareAlike 4.0 License, which allows others to remix, tweak, and build upon the work non-commercially, as long as appropriate credit is given and the new creations are licensed under the identical terms.

For reprints contact: reprints@medknow.com

How to cite this article: Karakurt A, Yildiz C. Predictive values of inflammatory cell ratios for complexity of coronary artery disease in patients with acute coronary syndrome. Int J Cardiovasc Acad 2018;4:70-6. 
complexity (CCAD) in patients with ACS, with contrasting results.

Therefore, the aim of the current study was to evaluate the relationship between NLR, PLR, MPVLR, MPVPR, and CCAD in patients with ACS, using SS I algorithm.

\section{Materials and Methods}

\section{Study population}

This study is a retrospective study based on medical record review. Between February 2014 and June 2017, 599 acute coronary disease patients who met all the inclusion criteria were admitted to our university hospital. None of the exclusion criteria were included in the study. Our study was in compliance with the Declaration of Helsinki, and it was approved by our university Local Research Ethics Committee.

ACS was diagnosed according to the criteria recommended by the 2015 ECS guidelines. ${ }^{[22]}$ The study population composed of patients with USAP, non-STEMI, and STEMI. Diagnosis of USAP was based on the chest pain suggesting USAP with or without ischemic electrocardiographic findings. The diagnosis of non-STEMI was made when characteristic angina pectoris lasted longer than $20 \mathrm{~min}$ with/without associated ST-segment depression of $\geq 0.1 \mathrm{mV}$ and/or T-wave inversion in two contiguous leads in the electrocardiogram and presence of increased troponin $\mathrm{T}$ level over the diagnostic cutoff value. STEMI was diagnosed in the presence of angina pectoris lasting more than $20 \mathrm{~min}$ that associated with ST-segment elevation of $\geq 1 \mathrm{~mm}$ in at least two contiguous limb leads or $\geq 2 \mathrm{~mm}$ in at least two contiguous chest leads.

Exclusion criteria consisted of patients with a history of trauma, surgery, malignancy, infectious diseases within 30 days before admission, hematologic disorders, rheumatologic diseases (systemic lupus erythematosus, rheumatoid arthritis, and Kawasaki disease), severe chronic or acute renal disease, hepatic failure, use of immunosuppressive agents within 3 weeks before study entry. Individuals with prior percutaneous or surgical revascularization were excluded from the study as SS had been validated only for patients with native CAD.

\section{Study protocol}

Demographic characteristics and venous blood samples parameters were recorded form the patient's file. All subjects were evaluated with complete blood count $(\mathrm{CBC})$, routine biochemical examination and ECG. The CBC parameters such as white blood count (WBC), hemoglobin ( $\mathrm{Hb}$ ), platelet count (PC), MPV, neutrophil, and lymphocyte were analyzed. The NLR, PLR, MPVLR, and MPVPR were calculated by dividing the absolute neutrophil count (NC) to the absolute lymphocyte count (LC), the absolute PC to absolute LC, MPV to the absolute LC, and MPV to the absolute PC, respectively. Fasting biochemical parameters such as the total cholesterol (TC), high-density lipoprotein, low-density lipoprotein (LDL), triglyceride (TG), and glucose levels were tested 1 day after hospital admission.

\section{Coronary angiography and SYNTAX score I}

Coronary angiography was performed by standard Judkins techniques through femoral approach. An invasive cardiologist evaluated the angiographic CD records using the SS system. Patients' CCAD score was calculated using an online calculator (http://www.syntaxscore.com/calculator/start.htm). Patients were divided into three groups according to their SS: low SS group (SSG) $(\leq 22)$, intermediate $\mathrm{SSG}^{[22-32]}$ and high $\operatorname{SSG}(\geq 33) \cdot{ }^{[23]}$

\section{Statistical analysis}

Data were tested for normal distribution and variance homogeneity using Levene's test. Categorical variables were expressed as absolute frequencies and percentages while continuous parametric variables were expressed as the mean and standard deviation, and continuous nonparametric variables were expressed as the median value and $25^{\text {th }}-75^{\text {th }}$ percentile. One-way ANOVA test was used to compare the continuous variables with parametric distribution. Kruskal-Wallis H-test was utilized to compare continuous variables with nonparametric distribution. Categorical variables were assessed by Chi-square test. Pearson correlation test was applied in the correlation analysis. Receiver operating characteristics (ROC) curve analysis was used for PLR and MPVLR. All statistical analyzes were performed by SPSS 23 (SPSS, Inc., Chicago, Illinois, USA). $P<0.05$ was considered statistically significant.

\section{ResULTS}

We conducted this single-center, medical record study through data retrieved between February 2014 and March 2018 at the cardiology department of the university hospital. A total of 599 (401 [66.9\%] males and 198 [33.1\%] females) patients with ACS were included in the study $(P<0.001)$. Patients were stratified into three groups according to their SS: low-SSG ( $n=436,72.8 \%$, mean age: $61.26 \pm 11.21)$, intermediate-SSG $(n=127,21.2 \%$, mean age: $66.65 \pm 8.8)$, and high-SSG ( $n=36.6 \%$, mean age: $73.47 \pm 8.6)$.

Demographic and clinical characteristics of these three groups are presented in Table 1 . The mean patient age was significantly higher in the high-SSG group than that in the low- and in-SSGs $(P<0.001)$. There was a significant difference in the number of male patients between the three groups $(P=0.01)$. The prevalence of diabetes mellitus and hypertension differed significantly between these three groups $(P<0.001$ and $P<0.001$, respectively). The mean of MCV, RDW, TC were significantly lower in the high-SSG group than that in the low- and in-SSG groups $(P=0.015, P=0.028, P=0.01)$. Urea and uric acid were significantly higher in the high-SSG group than that in the low- and in-SSG groups. The median of left ventricle ejection fraction and B-type natriuretic peptide were significantly lower in the high-SSG group than those in the low- and in-SSG groups $(P<0.001$ and $P=0.004$, respectively). However, the groups did not differ significantly with respect to body mass index; mean of SBP, diastolic blood pressure, pulse pressure, LDL, and TG. 


\begin{tabular}{|c|c|c|c|c|}
\hline & Low-SSG $(n=436)$ & In-SSG $(n=127)$ & High-SSG $(n=36)$ & $P$ \\
\hline Age (years) & $61.26 \pm 11.21$ & $66.65 \pm 8.8$ & $73.47 \pm 8.6$ & $<0.001$ \\
\hline Gender male, $n(\%)$ & $308(66.5)$ & $67(52.8)$ & $26(72.2)$ & 0.010 \\
\hline $\mathrm{BMI}\left(\mathrm{m}^{2} / \mathrm{kg}\right)$ & $28.43 \pm 4.75$ & $28.67 \pm 5.5$ & $27.79 \pm 3.91$ & 0.732 \\
\hline $\mathrm{DM}, n(\%)$ & $144(31.2)$ & $85(67.5)$ & $21(58.3)$ & $<0.001$ \\
\hline $\mathrm{HT}, n(\%)$ & $222(48.1)$ & $112(88.9)$ & $30(83.3)$ & $<0.001$ \\
\hline $\mathrm{SBP}(\mathrm{mmHg})$ & $121.8 \pm 24.69$ & $125.45 \pm 20.86$ & $122.54 \pm 19.48$ & 0.424 \\
\hline $\mathrm{DBP}(\mathrm{mmHg})$ & $76.02 \pm 13.2$ & $78.24 \pm 12.77$ & $76.54 \pm 13.18$ & 0.359 \\
\hline $\mathrm{PP}(\mathrm{mmHg})$ & $44.66 \pm 13.88$ & $47.22 \pm 13.13$ & $44.65 \pm 14.81$ & 0.283 \\
\hline $\mathrm{HGB}(\mathrm{mg} / \mathrm{dL})$ & $14.08 \pm 5.73$ & $13.07 \pm 1.65$ & $12.9 \pm 2.04$ & 0.164 \\
\hline HTC (fL) & $40.71 \pm 5.32$ & $39.13 \pm 4.57$ & $38.94 \pm 5.33$ & 0.015 \\
\hline MCV (fL) & $86.92 \pm 7.14$ & $86.94 \pm 6.06$ & $87.23 \pm 7.85$ & 0.978 \\
\hline RDW (\%) & $14.04 \pm 1.63$ & $14.25 \pm 1.52$ & $13.25 \pm 1.84$ & 0.028 \\
\hline PGL (mg/dL) & $137.81 \pm 71.1$ & $168.37 \pm 77.55$ & $142.03 \pm 81.44$ & $<0.001$ \\
\hline $\mathrm{TC}(\mathrm{mg} / \mathrm{dL})$ & $191.14 \pm 45.41$ & $177.74 \pm 39.14$ & $173.67 \pm 30.28$ & 0.010 \\
\hline $\mathrm{LDL}(\mathrm{mg} / \mathrm{dL})$ & $124.28 \pm 89.43$ & $109.63 \pm 34.64$ & $108.87 \pm 28.15$ & 0.132 \\
\hline HDL (mg/dL) & $39.22 \pm 10.76$ & $38.52 \pm 12.73$ & $37.79 \pm 12.61$ & 0.687 \\
\hline $\mathrm{TG}(\mathrm{mg} / \mathrm{dL})$ & $156.35 \pm 95.03$ & $162.56 \pm 88.78$ & $139.37 \pm 69.48$ & 0.438 \\
\hline $\mathrm{Na}(\mathrm{mmol} / \mathrm{L})$ & $136.34 \pm 3.85$ & $136.48 \pm 4.38$ & $136.55 \pm 4.82$ & 0.935 \\
\hline $\mathrm{K}(\mathrm{mmol} / \mathrm{L})$ & $4.28 \pm 0.54$ & $4.45 \pm 0.51$ & $4.32 \pm 0.53$ & 0.024 \\
\hline GGT (U/L) & $33.41 \pm 25.53$ & $32.10 \pm 38.87$ & $31.81 \pm 20.45$ & 0.906 \\
\hline $\mathrm{CB}(\mathrm{mg} / \mathrm{dL})$ & $0.19 \pm 0.10$ & $0.18 \pm 0.14$ & $0.26 \pm 0.17$ & 0.009 \\
\hline $\mathrm{TB}(\mathrm{mg} / \mathrm{dL})$ & $0.56 \pm 0.30$ & $0.48 \pm 0.29$ & $0.59 \pm 0.36$ & 0.067 \\
\hline Urea $(\mathrm{mg} / \mathrm{dL})$ & $30(24-38)$ & $35(27-46)$ & $39.45(29.25-54)$ & $<0.001$ \\
\hline Uric acid $(\mathrm{mg} / \mathrm{dL})$ & $5.4(4.6-6.23)$ & $5.2(4.5-6.45)$ & $5.75(5.2-8.5)$ & $0.094 *$ \\
\hline CK-MB (ng/mL) & $57.45(17.8-313.4)$ & $132.2(27.4-777.3)$ & $264(130.9-1241.8)$ & $<0.001$ \\
\hline T-I (ng/mL) & $3.62(1.64-10.31)$ & $5.3(2.11-14.69)$ & $6.19(2.67-33.88)$ & $0.007 *$ \\
\hline $\mathrm{BNP}(\mathrm{pg} / \mathrm{mL})$ & $224.45(82.29-704.05)$ & $558.3(136.9-1567.5)$ & $1071.85(230.25-4091.5)$ & $0.004 *$ \\
\hline $\mathrm{EF}(\%)$ & $56(50-60)$ & $54(45-58)$ & $50(40-57.75)$ & $<0.001^{*}$ \\
\hline SS & $15(12.5-17.5)$ & $27(24.5-29)$ & $36(34-38)$ & $<0.001^{*}$ \\
\hline
\end{tabular}

*Data are expressed as median $\left(25^{\text {th }}-75^{\text {th }}\right.$ percentiles $)$. BMI: Body mass index, BNP: B-type natriuretic peptide, CB: Conjugated Bilirubin, CK-MB: Creatine kinase-MB, DBP: Diastolic blood pressures, DM: Diabetes mellitus, FGL: Fasting glucose level, HDL: High-density lipoprotein, SS: Syntax score, High SSG: High SS group, HT: Hypertension, HTC: Hematocrit, In SSG: Intermediate SS group, K: Potassium, LDL: Low-density lipoprotein, Low SSG: Low SS group, Na: Sodium, PP: Pulse pressure, RDW: Red cell distribution width, SBP: Systolic blood pressure, TB: Total Bilirubin, TC: Total cholesterol, TG: Triglyceride, T-I: Troponin-I, EF: Ejection fraction, GGT: Gamma glutamil transferaz, MCV: Mean corpuscular volume, HGB: Hemoglobin

The inflammatory markers, ratio of inflammatory markers, MPVLR, MPVPR, and CRP of the ACS patients according to the SS are presented in Table 2. WBC, NC, LC, and NLR did not differ statistically between the three groups.

Although PC, MPV, and MPVPR did not differ significantly between these three groups. PLR and MPVLR were higher significantly in high-SSG group than those in the low-SSG and intermediate-SSG groups $(P=0.007$ and $P=0.029$, respectively).

The high-SSG group had higher CRP levels $(1.5 \pm 2.26 \mathrm{mg} / \mathrm{dl})$ than the intermediate-SSG group $(1.22 \pm 1.57 \mathrm{mg} / \mathrm{dl})$, and the intermediate-SSG group had higher CRP levels than the low SSG $(1.14 \pm 2.5 \mathrm{mg} / \mathrm{dl})(P<0.001)$.

Correlation analysis was performed to investigate the relationship between the SS and parameters (NLR, PLR, MPV, MPVLR, and MPVPR). A significant correlation was found between MPV, PLR, MPVLR, and SS ( $r=0.094$, $P=0.019 ; r=0.095, P=0.018$ and $r=0.112, P=0.005$, respectively) [Table 3, Figures 1 and 2].
Univariate regression analysis showed statistically significant but weak correlations between PLR, MPVLR and CCAD ( $\beta=0.009$ [95\% confidence interval [CI]: 0.002-0.016], $P=0.018$ and $\beta=0.267$ [95\% CI: $0.081-0.453$ ], $P=0.005$, respectively) [Table 4]. In addition, we performed multivariate regression analysis for variables that showed significance in the univariate model. Multivariate regression analysis revealed that MPVLR was not an independent predictor of CCAD (odds ratio [OR]. 1.070 [95\% CI: 0.918-1.065), $P=0.761)$, whereas PLR was a weak predictor for CCAD (OR: 1.003 [95\% CI: 1.001-1.006], $P=0.021$ ) [Table 4]. In the ROC curves analysis, the (area under the curve $[\mathrm{AUC}]=0.560$, 95\% CI: $0.508-0.612, P=0.023)$, with optimal cutoff value of 127.65 (sensitivity: $56.2 \%$, specificity: $51.6 \%$ ) for predicting CCAD [Table 5 and Figure 3].

\section{Discussion}

In this study, we only included patients with ACS (USAP, non-STEMI, and STEMI). This study was designed to 


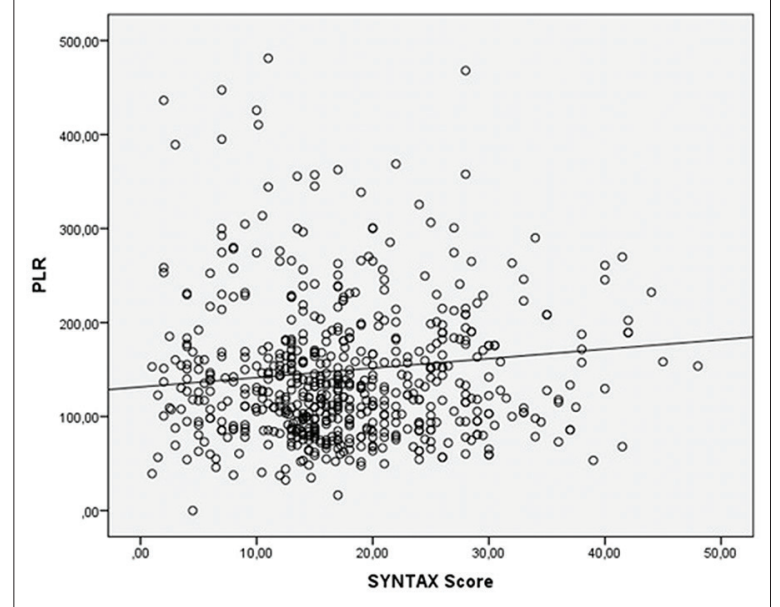

Figure 1: Correlation between platelet to lymphocyte and SYNTAX score $(r=0.095, P=0.018)$

\begin{tabular}{|c|c|c|c|c|}
\hline & $\begin{array}{l}\text { Low-SSG } \\
(n=436)\end{array}$ & $\begin{array}{c}\text { In-SSG } \\
(n=127)\end{array}$ & $\begin{array}{c}\text { High-SSG } \\
(n=36)\end{array}$ & $P$ \\
\hline WBC (K/uL) & $8.97 \pm 2.96$ & $8.9013 \pm 2.82$ & $8.46 \pm 2.45$ & 0.596 \\
\hline $\mathrm{NC}(\mathrm{K} / \mathrm{uL})$ & $6.07 \pm 2.66$ & $6.15 \pm 2.84$ & $5.77 \pm 2.26$ & 0.758 \\
\hline LC (K/uL) & $2.08 \pm 1.17$ & $1.96 \pm 0.90$ & $1.73 \pm 0.87$ & 0.139 \\
\hline PLT (K/uL) & $9.97 \pm 1.48$ & $10.29 \pm 1.54$ & $9.86 \pm 1.28$ & 0.085 \\
\hline MPV (fL) & $242.75 \pm 70.37$ & $255.87 \pm 87.13$ & $245.67 \pm 82.67$ & 0.218 \\
\hline NLR & $3.74 \pm 2.98$ & $4.11 \pm 3.89$ & $4.63 \pm 3.91$ & 0.179 \\
\hline PLR & $142.87 \pm 79.76$ & $163.23 \pm 111.55$ & $181.35 \pm 126.04$ & 0.007 \\
\hline MPVLR & $6.04 \pm 3.40$ & $6.70 \pm 4.06$ & $7.36 \pm 3.89$ & 0.029 \\
\hline MPVPR & $4.52 \pm 1.84$ & $4.44 \pm 1.61$ & $4.43 \pm 1.45$ & 0.881 \\
\hline CRP (mg/dL) & $1.14 \pm 2.5$ & $1.22 \pm 1.57$ & $1.5 \pm 2.26$ & $<0.001$ \\
\hline \multicolumn{5}{|c|}{$\begin{array}{l}\text { CRP: C-reactive proteins, LC: Lymphocyte count, MPV: Main platelet } \\
\text { volume, MPVLR: MPV to lymphocyte ratio, MPVPR: MPV to platelet } \\
\text { ratio, NC: Neutrophil count, NLR: Neutrophil to lymphocyte ratio, } \\
\text { PLR: Platelet to lymphocyte ratio, PLT: Platelet, SS: Syntax score, } \\
\text { WBC: White blood count, High SSG: High SS group, In SSG: Intermediate } \\
\text { SS group, Low SSG: Low SS group }\end{array}$} \\
\hline
\end{tabular}

investigate the relationship between NLR, PLR, MPVR, MPVLR, and CCAD in patients with ACS.

Main findings of our study were as follows: (1) although there was no correlation between NLR, MPVLR, and CCAD in ACS patients, (2) there was a weak positive correlation between PLR, MPVLR, and CCAD, (3) Univariate and multivariate regression analysis showed that MPVLR was not an independent predictor of CCAD, whereas PLR was a weak independent predictor of CCAD, and (4) PLR had a low sensitivity $(56.2 \%)$ and specificity $(51.6 \%)$ to predict intermediate and high anatomic CAD complexity ( $\mathrm{SS}>22$ ).

Ample research has shown that inflammation plays an important role in atherosclerotic CAD. Inflammatory cells are important at every stage of atherosclerotic lesions, their effector molecules accelerate progression of the lesions, and activation of inflammation can elicit ACS. ${ }^{[24,25]}$ In recent years, NLR, PLR,

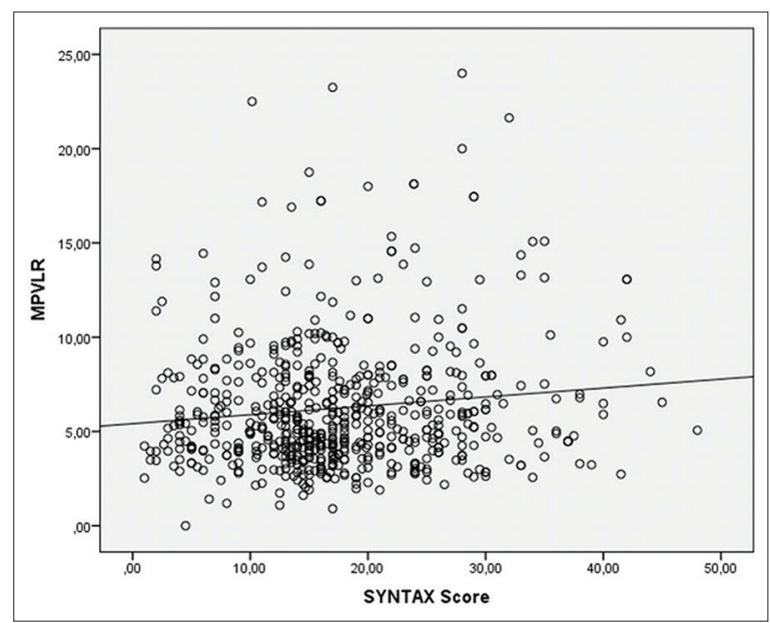

Figure 2: Correlation between mean platelet volume to lymphocyte ratio and SYNTAX score $(r=0.112, P=0.005)$

Table 3: Correlation analysis between complete blood count values, inflammatory cell ratios, and syntax score of the patients

\begin{tabular}{lcc}
\hline & \multicolumn{2}{c}{ SS } \\
\cline { 2 - 3 } & $\boldsymbol{r}$ & $\boldsymbol{P}$ \\
\hline WBC & -0.019 & 0.629 \\
NC & 0.007 & 0.860 \\
LC & -0.056 & 0.159 \\
PC & 0.033 & 0.411 \\
MPV & 0.094 & 0.019 \\
NLR & 0.060 & 0.131 \\
PLR & 0.095 & 0.018 \\
MPVLR & 0.112 & 0.005 \\
MPVPR & 0.022 & 0.587 \\
CRP & 0.031 & 0.440 \\
\hline WBC: Whit
\end{tabular}

WBC: White blood count, NC: Neutrophil count, LC: Lymphocyte count, PC: Platelet count, MPV: Main platelet volume, MPVLR: MPV to lymphocyte ratio, MPVPR: MPV to platelet ratio, NLR: Neutrophil to lymphocyte ratio, PLR: Platelet to lymphocyte ratio, CRP: C-reactive proteins, SS: Syntax score

MPVLR, and MPVPR, derivate indexes of CBC assays, have emerged as the new prognostic markers for various diseases such as cardiovascular disorders, malignant diseases, stroke subtypes, transient ischemic attack and pulmonary diseases including cystic fibrosis, chronic obstructive pulmonary disease, and acute pulmonary embolism. ${ }^{[26-28]}$ In this area, the most popular issue has certainly been CAD.

NLR and PLR have been shown to have a predictive value in the detection of CCAD in patients with stable CAD. ${ }^{[11,29-31]}$ Furthermore, they have been used in prediction of major adverse cardiovascular events (a new episode or a recurrence of myocardial infarction, UASP, development or worsening of heart failure, re-hospitalization, stroke, in hospital and long-term mortality), ${ }^{[31]}$ prognostication of CAD and evaluation of stent thrombosis risk. ${ }^{[32-36]}$ However, few studies have investigated the relationship between inflammatory cell 
Table 4: Independent predictors of high syntax score in acute coronary artery syndrome

\begin{tabular}{|c|c|c|c|c|}
\hline & \multicolumn{2}{|c|}{$\begin{array}{l}\text { Univariate regression } \\
\text { analysis }\end{array}$} & \multicolumn{2}{|c|}{$\begin{array}{c}\text { Multivariate regression } \\
\text { analysis }\end{array}$} \\
\hline & $\beta(95 \% \mathrm{CI})$ & $P$ & OR (95\% Cl) & $P$ \\
\hline NLR & $0.159(-0.048-0.365)$ & 0.131 & - & \\
\hline PLR & $0.009(0.002-0.016)$ & 0.018 & $1.003(1.001-1.006)$ & 0.021 \\
\hline MPVLR & $0.267(0.081-0.453)$ & 0.005 & $1.070(0.918-1.065)$ & 0.761 \\
\hline MPVPR & $10.492(-27.391-48.375)$ & 0.587 & - & - \\
\hline
\end{tabular}

Table 5: Receiver operating characteristic curves of platelet to lymphocyte ratio and main platelet volume to lymphocyte ratio for predicting coronary artery disease complexity using syntax score $=22$ cutoff value

\begin{tabular}{lccccc}
\hline \multicolumn{5}{c}{ Area under the curve } \\
$\begin{array}{l}\text { Test result } \\
\text { variables }\end{array}$ & Area & SD & $\boldsymbol{P}$ & \multicolumn{2}{c}{$\mathbf{9 5 \%} \mathbf{~ C l}$} \\
\cline { 5 - 6 } & & & & Lower bound & Upper bound \\
\hline NLR & 0.521 & 0.027 & 0.418 & 0.469 & 0.574 \\
PLR & 0,560 & 0.027 & 0.023 & 0.508 & 0.612 \\
MPVLR & 0.553 & 0.027 & 0.044 & 0.501 & 0.606 \\
MPVPR & 0.495 & 0.027 & 0.864 & 0.443 & 0.548 \\
\hline
\end{tabular}

MPV: Main platelet volume, MPVLR: MPV to lymphocyte ratio, MPVPR: MPV to platelet ratio, NLR: Neutrophil to lymphocyte ratio, PLR: Platelet to lymphocyte ratio, SD: Standard deviation, CI: Confidence interval

ratios and CCAD in ACS patients, and findings of these studies were insufficient to predict CCAD.

Chen et al. ${ }^{[37]}$ evaluated NLR in 2976 CAD patients and 571 healthy controls. CCAD was assessed using Gensini score. A cutoff value of 2.04 for NLR predicted severe CAD according to Gensini score. In that study, acute and chronic CAD were evaluated together; inflammatory response in chronic CAD was different from ACS; hence, the results of this study could not be generalized to ACS patients.

Another study performed by Soylu et al. ${ }^{[13]}$ investigated the relationship between NLR and SS in patients with non-STEMI. Patients were divided into three groups according to their NLR (NLR <2.6, NLR = 2.6-4.5, and NLR >4.5). Patients with high-NLR had higher SS than those with intermediate and low-NLR. Moreover, high NLR values were strong predictors of the in-hospital mortality in non-STEMI patients. Although they found a positive correlation between NLR and SS $(r=0.253 P=0.001)$, independent predictive value of NLR for high SS was not investigated. The presence of correlation between NLR and SS did not mean that high NLR had a predictive value for CCAD.

Kurtul et al. ${ }^{[38]}$ assessed the relationship between MPV, PLR and severity of CAD in patients with non-STEMI by using SS. NLR was found to be an independent predictor of severe

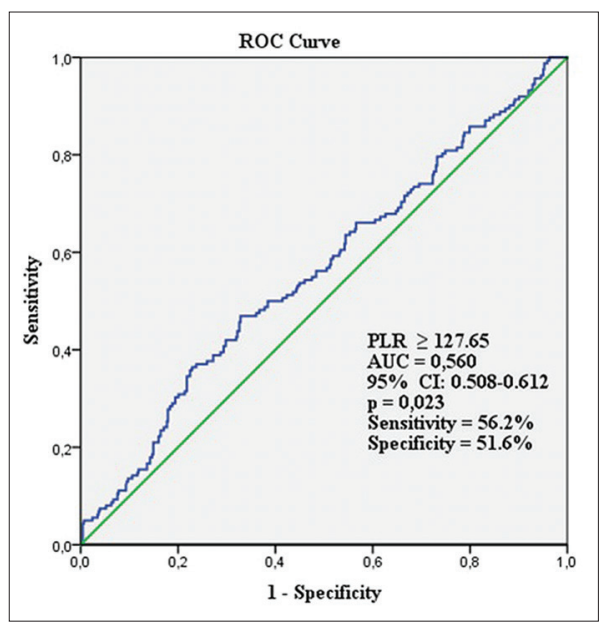

Figure 3: Receiver operating characteristics curves for the platelet to lymphocyte ratio value in the prediction of intermediate and high SYNTAX Score using $=22$ cutoff value. AUC: Area under the curve, Cl: Confidence interval

atherosclerosis (coefficient $\beta=0.380,95 \%$ CI: $1.165-1.917$, $P<0.001$ ), whereas MPV did not have such a predictive value (coefficient $\beta=1.010,95 \% \mathrm{CI}$ : $0.774-1.318, P=0.941$ ).

Kurtul A et al. ${ }^{[12]}$ divided the 1016 non-STEMI patients into two groups: group 1 composed of patients with low SS (SS <22), group 2 composed of patients with intermediate and high SS. They found a statistically significant difference with respect to PLR between the two groups, and a positive correlation was observed between PLR and SS $(P<0,001)$. Increased PLR was an independent predictor for high SS in non-STEMI patients $(\mathrm{OR}=1.018,95 \% \mathrm{CI}: 1.013-1.023, P<0.001)$. Moreover, in-hospital mortality was higher in group 2 than that in group $1(\mathrm{OR}=1.004,95 \% \mathrm{CI}: 1.001-1.008, P=0.032)$.

In our study, except for a weak positive correlation between PLR and CCAD, no correlation was observed with any of the parameters measured. According to both univariate and multivariate analysis results, PLR was a weak predictor of CCAD in ACS patients. The ROC analysis results confirmed the limited predictive value of PLR for CCAD in patients with ACS. Our findings contradicted the previous studies, ${ }^{[13,37,38]}$ except for the study by Kurtul et al. ${ }^{[12]}$ which was partially in concordance with our results.

Recent research has shown that inflammation is an integral part of atherosclerotic CAD. The degree of inflammatory activity depends on the characteristics of the atherosclerotic lesion. ${ }^{[2]}$ Plaque analysis has demonstrated less local and systemic inflammatory activity in silent atherosclerotic (noncomplicated and nonvulnerable) plaque than complicated plaque. ${ }^{[39]}$ It has been shown that ACS patients have higher levels of inflammatory cells and mediators including T-cell, CRP, interleukin-6, fibrinogen, interleukin-7, interleukin-8, soluble CD40 ligand, and C-reactive protein-related protein pentraxin-3 compared to patients with stable CAD, both systemically and within the lesion, suggesting the role of these mediators in atherosclerotic 
plaque rupture. ${ }^{[39-49]}$ High levels of inflammatory mediators were associated with increased cardiovascular mortality and adverse cardiovascular events. ${ }^{[45-47]}$ Increased levels of these mediators did not result from CCAD; rather they resulted from inflammatory response that was triggered by plaque rupture. ${ }^{[2-46]}$ In the light of these data, it could be concluded that the presence of stable, non-complicated CAD was associated with both systemic and local low-grade inflammation. However, clinical forms of ACS were associated with high-grade inflammation, both systemically and locally. Overall, the existence of noncorrelation between NLR, PLR, MPVLR, MPVLR and CCAD was an expected result. Stable CAD patients with low-grade inflammatory activity might have higher CCAD; ACS patients with high-grade inflammatory activity might have lower CCAD, and vice versa. As the degree of inflammatory response depended on plaque complication (vulnerability, erosion, and rupture) in both patient groups, the circulating levels of inflammatory markers would differ between them.

\section{Study limitations}

The present study had several limitations. First, our study was retrospective, cross-sectional, and was based on patient file data. However, our study population consisted of a sufficient number of patients with ACS. Second, NLR PLR, MPVLR, and MPVPR were analyzed from the first blood samples at hospital admission rather than several samples at different time intervals. Third, these ratios were considerably affected by many factors, including dehydration, overhydration, diluted blood specimens, and in vitro blood specimen handling. Finally, the results of this study could be generalized for all ACS but not for USAP, non-STEMI, or STEMI. Therefore, a separate study was needed to evaluate the relationship between inflammatory markers and CCAD for each subgroup of patients.

\section{Conclusion}

ACS was almost always associated with rupture of an atherosclerotic plaque and outburst of systemic markers of inflammation. Since, patients with ACS might have both less complex CAD morphology and high levels of inflammatory response; they might have no correlation between them. Therefore, NLR, PLR, MPVLR, MPVPR could not be used for prediction of CCAD in patients with ACS.

\section{Financial support and sponsorship}

Nil.

\section{Conflicts of interest}

There are no conflicts of interest.

\section{RefERENCES}

1. Ross R. Atherosclerosis - An inflammatory disease. N Engl J Med 1999;340:115-26.

2. Wong BW, Meredith A, Lin D, McManus BM. The biological role of inflammation in atherosclerosis. Can J Cardiol 2012;28:631-41.

3. Wang T, Palucci D, Law K, Yanagawa B, Yam J, Butany J.
Atherosclerosis: pathogenesis and pathology. Diagn Histopathol 2012;18:461-7.

4. Libby P, Ridker PM, Maseri A. Inflammation and atherosclerosis. Circulation 2002;105:1135-43.

5. Mulvihill NT, Foley JB. Inflammation in acute coronary syndromes. Heart 2002;87:201-4.

6. Sianos G, Morel MA, Kappetein AP, Morice MC, Colombo A, Dawkins K, et al. The SYNTAX score: An angiographic tool grading the complexity of coronary artery disease. EuroIntervention 2005;1:219-27.

7. Yadav M, Palmerini T, Caixeta A, Madhavan MV, Sanidas E, Kirtane AJ, et al. Prediction of coronary risk by SYNTAX and derived scores: Synergy between percutaneous coronary intervention with taxus and cardiac surgery. J Am Coll Cardiol 2013;62:1219-30.

8. Garg S, Sarno G, Garcia-Garcia HM, Girasis C, Wykrzykowska J, Dawkins KD, et al. A new tool for the risk stratification of patients with complex coronary artery disease: The clinical SYNTAX score. Circ Cardiovasc Interv 2010;3:317-26.

9. Safarian H, Alidoosti M, Shafiee A, Salarifar M, Poorhosseini H, Nematipour E, et al. The SYNTAX score can predict major adverse cardiac events following percutaneous coronary intervention. Heart Views 2014;15:99-105.

10. Girasis C, Garg S, Räber L, Sarno G, Morel MA, Garcia-Garcia HM, et al. SYNTAX score and clinical SYNTAX score as predictors of very long-term clinical outcomes in patients undergoing percutaneous coronary interventions: A substudy of SIRolimus-eluting stent compared with pacliTAXel-eluting stent for coronary revascularization (SIRTAX) trial. Eur Heart J 2011;32:3115-27.

11. Akboga MK, Canpolat U, Yayla C, Ozcan F, Ozeke O, Topaloglu S, et al. Association of platelet to lymphocyte ratio with inflammation and severity of coronary atherosclerosis in patients with stable coronary artery disease. Angiology 2016;67:89-95.

12. Kurtul A, Murat SN, Yarlioglues M, Duran M, Ergun G, Acikgoz SK, et al. Association of platelet-to-lymphocyte ratio with severity and complexity of coronary artery disease in patients with acute coronary syndromes. Am J Cardiol 2014;114:972-8.

13. Soylu K, Gedikli Ö, Dagasan G, Aydin E, Aksan G, Nar G, et al. Neutrophil-to-lymphocyte ratio predicts coronary artery lesion complexity and mortality after non-ST-segment elevation acute coronary syndrome. Rev Port Cardiol 2015;34:465-71.

14. Tsiara S, Elisaf M, Jagroop IA, Mikhailidis DP. Platelets as predictors of vascular risk: Is there a practical index of platelet activity? Clin Appl Thromb Hemost 2003;9:177-90.

15. Ornek E, Kurtul A. Relationship of mean platelet volume to lymphocyte ratio and coronary collateral circulation in patients with stable angina pectoris. Coron Artery Dis 2017;28:492-7.

16. Park JJ, Jang HJ, Oh IY, Yoon CH, Suh JW, Cho YS, et al. Prognostic value of neutrophil to lymphocyte ratio in patients presenting with ST-elevation myocardial infarction undergoing primary percutaneous coronary intervention. Am J Cardiol 2013;111:636-42.

17. Bajari R, Tak S. Predictive prognostic value of neutrophil-lymphocytes ratio in acute coronary syndrome. Indian Heart J 2017;69 Suppl 1:S46-50.

18. Gazi E, Bayram B, Gazi S, Temiz A, Kirilmaz B, Altun B, et al. Prognostic value of the neutrophil-lymphocyte ratio in patients with ST-elevated acute myocardial infarction. Clin Appl Thromb Hemost 2015;21:155-9.

19. Azab B, Shah N, Akerman M, McGinn JT Jr. Value of platelet/lymphocyte ratio as a predictor of all-cause mortality after non-ST-elevation myocardial infarction. J Thromb Thrombolysis 2012;34:326-34.

20. Cho KI, Ann SH, Singh GB, Her AY, Shin ES. Combined usefulness of the platelet-to-lymphocyte ratio and the neutrophil-to-lymphocyte ratio in predicting the long-term adverse events in patients who have undergone percutaneous coronary intervention with a drug-eluting stent. PLoS One 2015;10:e0133934.

21. Azab B, Zaher M, Weiserbs KF, Torbey E, Lacossiere K, Gaddam S, et al. Usefulness of neutrophil to lymphocyte ratio in predicting short- and long-term mortality after non-ST-elevation myocardial infarction. Am J Cardiol 2010;106:470-6.

22. Roffi M, Patrono C, Collet JP, Mueller C, Valgimigli M, Andreotti F, et al. 2015 ESC guidelines for the management of acute coronary syndromes in patients presenting without persistent ST-segment 
elevation: Task force for the management of acute coronary syndromes in patients presenting without persistent ST-segment elevation of the European Society of Cardiology (ESC). Eur Heart J 2016;37:267-315.

23. Serruys PW, Morice MC, Kappetein AP, Colombo A, Holmes DR, Mack MJ, et al. Percutaneous coronary intervention versus coronary-artery bypass grafting for severe coronary artery disease. N Engl J Med 2009;360:961-72.

24. Libby P. Changing concepts of atherogenesis. J Intern Med 2000;247:349-58.

25. Zakynthinos E, Pappa N. Inflammatory biomarkers in coronary artery disease. J Cardiol 2009;53:317-33.

26. O'Brien CE, Price ET. The blood neutrophil to lymphocyte ratio correlates with clinical status in children with cystic fibrosis: A retrospective study. PLoS One 2013;8:e77420.

27. Günay E, Sarınç Ulaşlı S, Akar O, Ahsen A, Günay S, Koyuncu T, et al. Neutrophil-to-lymphocyte ratio in chronic obstructive pulmonary disease: A retrospective study. Inflammation 2014;37:374-80.

28. Kayrak M, Erdoğan HI, Solak Y, Akilli H, Gül EE, Yildirim O, et al. Prognostic value of neutrophil to lymphocyte ratio in patients with acute pulmonary embolism: A restrospective study. Heart Lung Circ 2014;23:56-62.

29. Açar G, Fidan S, Uslu ZA, Turkday S, Avci A, Alizade E, et al. Relationship of neutrophil-lymphocyte ratio with the presence, severity, and extent of coronary atherosclerosis detected by coronary computed tomography angiography. Angiology 2015;66:174-9.

30. Zhou D, Wang G, Fan Y, Wan Z, Liu X. Platelet to lymphocyte ratio is associated with the severity of coronary artery disease and clinical outcomes of percutaneous coronary intervention in the Chinese Han population. Exp Ther Med 2017;13:731-8.

31. Dentali F, Nigro O, Squizzato A, Gianni M, Zuretti F, Grandi AM, et al. Impact of neutrophils to lymphocytes ratio on major clinical outcomes in patients with acute coronary syndromes: A systematic review and meta-analysis of the literature. Int J Cardiol 2018;266:31-7.

32. Huang G, Zhao JL, Du H, Lan XB, Yin YH. Coronary score adds prognostic information for patients with acute coronary syndrome. Circ J 2010;74:490-5.

33. Papa A, Emdin M, Passino C, Michelassi C, Battaglia D, Cocci F, et al. Predictive value of elevated neutrophil-lymphocyte ratio on cardiac mortality in patients with stable coronary artery disease. Clin Chim Acta 2008:395:27-31.

34. Osadnik T, Wasilewski J, Lekston A, Strzelczyk J, Kurek A, Gonera M, et al. The platelet-to-lymphocyte ratio as a predictor of all-cause mortality in patients with coronary artery disease undergoing elective percutaneous coronary intervention and stent implantation. J Saudi Heart Assoc 2015;27:144-51.

35. Poludasu S, Cavusoglu E, Khan W, Marmur JD. Neutrophil to lymphocyte ratio as a predictor of long-term mortality in African Americans undergoing percutaneous coronary intervention. Clin Cardiol 2009;32:E6-10.
36. Ayça B, Akın F, Celik O, Sahin I, Yildiz SS, Avci II, et al. Neutrophil to lymphocyte ratio is related to stent thrombosis and high mortality in patients with acute myocardial infarction. Angiology 2015;66:545-52.

37. Chen J, Chen MH, Li S, Guo YL, Zhu CG, Xu RX, et al. Usefulness of the neutrophil-to-lymphocyte ratio in predicting the severity of coronary artery disease: A Gensini score assessment. J Atheroscler Thromb 2014;21:1271-82

38. Kurtul S, Sarli B, Baktir AO, Demirbas M, Saglam H, Doğan Y, et al. Neutrophil to lymphocyte ratio predicts SYNTAX score in patients with non-ST segment elevation myocardial infarction. Int Heart J 2015;56:18-21.

39. Hansson GK. Inflammation, atherosclerosis, and coronary artery disease. N Engl J Med 2005;352:1685-95.

40. Liuzzo G, Goronzy JJ, Yang H, Kopecky SL, Holmes DR, Frye RL, et al. Monoclonal T-cell proliferation and plaque instability in acute coronary syndromes. Circulation 2000;101:2883-8.

41. Ridker PM, Hennekens CH, Buring JE, Rifai N. C-reactive protein and other markers of inflammation in the prediction of cardiovascular disease in women. N Engl J Med 2000;342:836-43.

42. Liu J, Sukhova GK, Sun JS, Xu WH, Libby P, Shi GP. Lysosomal cysteine proteases in atherosclerosis. Arterioscler Thromb Vasc Biol 2004;24:1359-66.

43. Liuzzo G, Biasucci LM, Gallimore JR, Grillo RL, Rebuzzi AG, Pepys $\mathrm{MB}$, et al. The prognostic value of $\mathrm{C}$-reactive protein and serum amyloid a protein in severe unstable angina. $\mathrm{N}$ Engl $\mathrm{J}$ Med 1994;331:417-24

44. Biasucci LM, Vitelli A, Liuzzo G, Altamura S, Caligiuri G, Monaco C, et al. Elevated levels of interleukin-6 in unstable angina. Circulation 1996;94:874-7.

45. Aukrust P, Müller F, Ueland T, Berget T, Aaser E, Brunsvig A, et al. Enhanced levels of soluble and membrane-bound CD40 ligand in patients with unstable angina. Possible reflection of T lymphocyte and platelet involvement in the pathogenesis of acute coronary syndromes. Circulation 1999; 100:614-20.

46. Lindahl B, Toss H, Siegbahn A, Venge P, Wallentin L. Markers of myocardial damage and inflammation in relation to long-term mortality in unstable coronary artery disease. FRISC Study Group. Fragmin during instability in coronary artery disease. N Engl J Med 2000;343:1139-47.

47. Wilhelmsen L, Svärdsudd K, Korsan-Bengtsen K, Larsson B, Welin L, Tibblin $\mathrm{G}$, et al. Fibrinogen as a risk factor for stroke and myocardial infarction. N Engl J Med 1984;311:501-5.

48. Peri G, Introna M, Corradi D, Iacuitti G, Signorini S, Avanzini F, et al. PTX3, A prototypical long pentraxin, is an early indicator of acute myocardial infarction in humans. Circulation 2000;102:636-41.

49. Damås JK, Waehre T, Yndestad A, Otterdal K, Hognestad A, Solum NO, et al. Interleukin-7-mediated inflammation in unstable angina: Possible role of chemokines and platelets. Circulation 2003;107:2670-6. 